\title{
A gente é um passador de informação: práticas educativas de agentes de combate a endemias no serviço de controle de zoonoses em Belo Horizonte, $\mathbf{M G}^{\prime}$
}

\author{
We are information dealers: educational practices of \\ endemic diseases' battling agents at a service of zoonoses \\ control in Belo Horizonte, Brazil
}

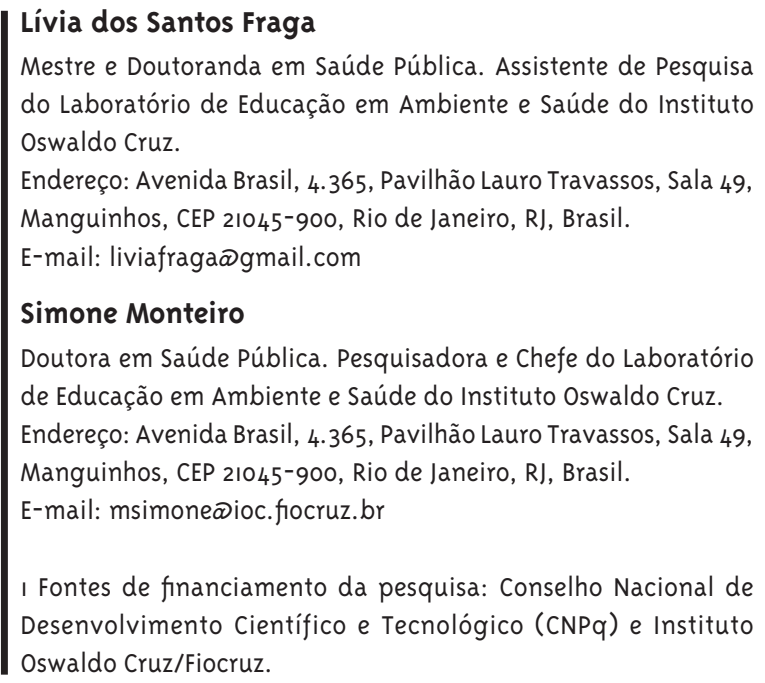

\section{Resumo}

As zoonoses ocupam importante lugar entre as causas de adoecimento no Brasil. A revisão histórica das diretrizes dos programas governamentais de controle destas enfermidades revela avanços, mas a sua operacionalização no âmbito estadual e municipal depende de fatores socioambientais, institucionais e epidemiológicos. Esta pesquisa objetiva analisar as práticas educativas desenvolvidas por agentes de combate a endemias (ACEs), a partir de um estudo de caso numa região de Belo Horizonte, MG. A investigação envolveu análise documental, dois meses de observação participante da rotina de trabalho dos agentes e entrevistas com 16 ACEs e dois coordenadores do serviço. A região apresentou diversos elementos ambientais, socioeconômicos e culturais associados à ocorrência de zoonoses, mas tais fatores não foram considerados nas orientações dos ACEs aos moradores. Nas ações educativas, predomina a transmissão de informações técnico-científicas relacionadas ao controle de focos, criadouros de vetores e reservatórios de zoonoses; os saberes e a lógica popular não são valorizados. Apesar da centralidade do papel educativo dos ACEs no discurso institucional, as atividades educativas dos agentes são limitadas diante das lacunas na formação profissional, na estrutura organizacional do serviço e no modelo de gerenciamento, pautado em indicadores quantitativos de produtividade. Para compreender a resistência da população ao discurso técnico-científico e incrementar as atividades edu- 
cativas dos ACEs, é preciso mudar a organização do serviço e desenvolver cursos de formação dos ACEs, centrados na multideterminação do processo saúde-doença, na importância do contexto socioeconômico e ambiental no controle das zoonoses e na educação participativa.

Palavras-chave: Educação em Saúde; Zoonoses; Agentes Comunitários de Saúde.

\section{Abstract}

Zoonoses have an important place among illnesses' causes in Brazil. A historical review of governmental programs guidelines to control such diseases reveals advances, but their implementation at the municipal and state level depends on socio-environmental factors and on institutional and epidemiological characteristics. This research aims to analyze the educational practices developed by agents that fight endemic diseases (ACE) through a case study in one of Belo Horizonte's burroughs, MG. The research involved documental analysis, two months of observation of ACE work and interviews with $16 \mathrm{ACE}$ and two coordinators of the service. The region presented several environmental, socioeconomics and cultural elements associated with the occurrence of zoonoses, but these factors were not considered by ACE. The educational activities' developed by them were based on the transmission of technical-scientific information related to the control of zoonoses' vectors and reservoirs ; the knowledge of the population was not valued. In spite of the central place attributed to ACE's educational activities in the institutional discourse, those actions are limited by gaps in their training process and by the organizational structure of the service and management model, based on quantitative indicators of productivity. In order to understand the resistance of the population to technical-scientific discourse and to improve ACE's educational activities it is necessary to review the service organization and to develop a training process for them based on the multiple determinations of health-disease process, on the importance of environmental and socioeconomic contexts in zoonoses control and on participatory education.

Keywords: Health Education; Zoonoses; Community Health Workers. 
No Brasil, embora haja predominância das doenças crônico-degenerativas, as enfermidades transmissíveis, como as zoonoses, ocupam posição importante entre as causas de adoecimento (Schramm e col., 2004). Além dos processos biológicos de seleção e adaptação de vetores, parasitas e hospedeiros, contribuem para a (re)emergência de zoonoses a urbanização, o modelo de desenvolvimento e a organização das cidades para enfrentamento do acúmulo humano no País. Salienta-se que 15,6 milhões de pessoas migraram do campo para as cidades na década de 1970, sendo que em 2010, 84\% da população brasileira morava nas cidades (IBGE, 2011). Importante destacar que a população imigrante do campo levou para o meio urbano hábitos do meio rural, como a criação de animais domésticos e o cultivo de alimentos.

A relação entre a urbanização e os problemas sanitários e de saúde da população está diretamente vinculada ao modelo perverso de desenvolvimento, que favorece a ocupação desordenada de áreas por grupos sociais desfavorecidos (Porto, 2008). Esse quadro de exclusão social encontra determinantes nas políticas econômicas e sociais que caracterizam o cenário nacional, a partir da década de 1970, contribuindo para a conformação de um processo de transição epidemiológica, com a transferência de perfis de morbimortalidade característicos do meio rural para o ambiente urbano (Belavicqua e col., 2001). Um exemplo é a leishmaniose visceral (LV), doença estreitamente relacionada à pobreza e, inicialmente, caracterizada como endemia rural, associada aos bolsões de pobreza característicos do Nordeste. Atualmente é encontrada em áreas metropolitanas, como Rio de Janeiro e Belo Horizonte. Bangladesh, Brasil, Etiópia, Índia, Nepal e Sudão juntos são responsáveis por 9o\% do total de casos notificados da doença no mundo (WHO, 2010).

A análise histórica das políticas e das ações de controle de zoonoses no Brasil permitiu revelar o predomínio do foco nos elementos biológicos, nos componentes do ciclo das zoonoses e na responsabilização da população por sua saúde. Tal perspectiva contribui para ocultar a responsabilidade do Estado em prover condições básicas de vida para a população e a complexidade dos fatores envolvidos no aparecimento de casos deste grupo de enfermidades, limitando o problema à esfera individual (Oliveira e Valla, 2001).

A partir do século XX, a prioridade na área de saúde foi buscar formas de combater doenças e não estratégias para fortalecer o organismo como um todo. Tal foco se refletiu nas práticas de educação em saúde, que na maioria das vezes deixavam de lado o interesse sobre o indivíduo, seus hábitos, nível social e condições de vida e baseavam-se apenas no conteúdo que deveria ser repassado pelo educador. Especialmente sobre o controle de zoonoses no final da década de 1980, o componente educativo mantinha-se rígido e atento ao combate da doença, à importância da vacinação e ao comparecimento da população aos postos volantes espalhados pela cidade durante os dias de campanha. No entanto, não relacionava e nem alertava a população sobre os fatores ambientais e sociais ligados ao risco de ocorrência de doenças (Vasconcelos, 2002).

A partir da década de 1980, são identificados avanços nas políticas voltadas ao controle de zoonoses em função da ampliação do conceito de saúde e doença e da pressão da sociedade civil organizada. Após a implementação do processo de descentralização das endemias (até então de responsabilidade da Fundação Nacional de Saúde - Funasa), o Ministério da Saúde vem investindo recursos e apoiando os municípios para implantação e implementação da rede. Embora haja empenho dos órgãos e profissionais de saúde pública, este esforço ainda está desvinculado da análise das condições de vida e das representações e práticas dos grupos sociais. A Secretaria de Vigilância em Saúde (Brasil, 2007) reconhece que a atuação dos Centros de Controle de Zoonoses (CCZ) na educação em saúde e na mobilização social para as zoonoses são pouco usuais na realidade dos serviços (Ribeiro e col., 2004; Uchoa e col., 200o). A educação em saúde é um dos campos de prática e conhecimento do setor de saúde que mais têm se ocupado com a criação de vínculos entre a ação médica e o pensar e fazer cotidianos da população no âmbito das políticas e programas de Saúde Pública (Santos, 2003).

Diante das diversas concepções de educação em saúde, este estudo tomou como referência os fundamentos do modelo construtivista e problematizador. Segundo essa perspectiva, é preciso 
envolver os indivíduos na construção de práticas educativas, levá-los a uma atitude crítica, analítica e responsável a respeito do mundo que os cerca, formando cidadãos e não apenas espectadores, conforme argumenta Freire (2011). Para o autor, a educação não deve ser uma forma de exercício de poder, em que um saber (científico) é imposto pelo educador de forma opressora, pois o educando é sujeito no processo educativo e dotado de saber não menos legítimo. Desse modo, a educação problematizadora prioriza as mudanças sociais e assume que os riscos e doenças são frutos dos complexos e mórbidos processos sociais e culturais da humanidade contemporânea (industrialização predadora, saturação urbana, cultura consumista de massas). Tais processos precisam ser enfrentados por meio de políticas reguladoras da própria atividade econômica e não apenas com ações de atenção à saúde e/ou de educação normativa. 0 conhecimento dos componentes da cadeia epidemiológica (parasita, transmissão, hospedeiro e ambiente) é importante, mas necessita ser trabalhado a partir do contexto social e econômico das comunidades (Santos, 2005).

Pela análise das características socioeconômicas e culturais e pelo envolvimento ativo, respeitoso e emancipador dos atores de uma dada comunidade, as instituições de saúde têm o potencial de desenvolver programas educativos a partir da realidade local. Para tanto, cabe conhecer os fatores determinantes dos riscos e agravos e as crenças e conhecimentos dos habitantes locais na construção de meios para solucionar os problemas. Diante das questões estruturais relacionadas à situação de saúde, faz-se necessário um trabalho intersetorial. As bases técnicas e científicas podem contribuir para compreensão das causas, efeitos e soluções viáveis, mas precisam ser articuladas com a realidade local (Valla, 1998).

Tendo em vista os desafios assinalados - a (re) emergência de zoonoses e as limitações do discurso normativo centrado no repasse de informações técnico-científicas, na responsabilidade individual e nos determinantes biológicos relacionados à ocorrência de zoonoses - este estudo objetiva promover uma reflexão acerca dos programas e ações educativos voltados ao controle de zoonoses, a partir de um estudo de caso. São inúmeros os estudos quantitativos que enfocam a dimensão individual do problema e a necessidade de ações educativas voltadas às mudanças de comportamento dos indivíduos. De forma complementar, os estudos qualitativos podem contribuir para a elaboração de estratégias de enfrentamento e superação dos desafios indicados, com base na compreensão das práticas sociais dos sujeitos que integram a realidade concreta e simbólica.

\section{Metodologia}

Trata-se de um estudo de caso orientado pela abordagem qualitativa, que possibilita a pesquisa sobre grupos humanos em seu contexto, ou seja, indivíduos em sociedade, suas relações e instituições, história e produção simbólica (Minayo, 2010). O caso selecionado foi o serviço de controle de zoonoses em uma das áreas de abrangência da Secretaria Municipal de Saúde de Belo Horizonte, Minas Gerais (SMSA-BH).

A escolha por Belo Horizonte deu-se em função dos altos índices de leishmaniose visceral da região e da organização do serviço de controle de zoonoses, que é descentralizado e acompanha o recorte territorial da Atenção Básica. Para se chegar ao território aonde as ações educativas são realizadas, foi necessário selecionar a área de abrangência (AA) para estudo. Em função da facilidade de acesso e da indicação da Gerência Regional de Controle de Zoonoses (GERCZO), selecionou-se a área doravante denominada de Morros Ávidos (nome fictício).

As estratégias de coleta de dados foram definidas e trianguladas, visando à apreensão das diversas dimensões da realidade (Malinowski, 1984). Para tanto, a investigação envolveu: análise de documentos da Secretaria Municipal de Saúde, da GERCZO de Belo Horizonte e dados dos censos de 2000 e 2010 do Instituto Brasileiro de Geografia e Estatística (IBGE) $)^{2}$ para caracterização do território; observação participante, durante dois meses, do trabalho das equipes de zoonoses atuantes em Morros Ávidos

2 Apenas os dados sobre a população e o tipo de domicílio do censo 2010 estavam disponíveis no momento da pesquisa (outubro de 2011). As informações referentes ao saneamento básico no local datam do censo de 2000. 
e entrevistas individuais semiestruturadas com dois coordenadores das equipes de controle de zoonoses e 16 agentes de combate a endemias - número que corresponde a todos os ACEs atuantes na área de estudo -, acerca do perfil socioeconômico; identidade e formação profissional dos ACEs; e da sua atuação profissional (rotina, gerenciamento de atividades, desenvolvimento de práticas educativas). A observação participante contribuiu para estabelecimento de uma relação de confiança com os ACEs e facilitou a formulação de perguntas adequadas ao contexto durante as entrevistas (Thompson, 1992).

A análise dos dados foi orientada pela análise temática de conteúdo (Bardin, 2009). Para tanto, as entrevistas foram transcritas integralmente e lidas exaustivamente, assim como o diário de campo. As informações provenientes das entrevistas, das observações de campo e da análise documental foram organizadas através da identificação de núcleos de sentido e da categorização temática (Minayo, 2010). Tal processo foi norteado pela comparação entre as atividades realizadas pelos ACEs em campo, aquelas relatadas por eles e as previstas em seu quadro de atribuições e pelos fatores que limitaram a execução das ações. A conjugação dos dados coletados com os pressupostos e reflexões indicados na revisão bibliográfica permitiram reforçar ou refutar os argumentos elaborados e a construção de novas interpretações, visando à compreensão das concepções e práticas educativas dos ACEs.

A pesquisa foi submetida aos Comitês de Ética em Pesquisa em Seres Humanos (CEPs) da Escola Nacional de Saúde Pública Sérgio Arouca e da Secretaria Municipal de Saúde de Belo Horizonte (CAEE o101.0.031.410-11).

\section{Resultados e discussão}

\section{Características socioambientais e organização do serviço}

A área de abrangência de Morros Ávidos envolve 20 setores censitários, dispostos em três diferentes bairros de características históricas semelhantes: espaços de ocupação antiga e tipicamente popular (ocupação pela classe operária), cuja população enfrentou a escassez ou ineficiência dos serviços básicos, como abastecimento de água, esgoto e transporte coletivo (Arreguy e Ribeiro, 2008). A infraestrutura foi modificada, apesar de persistirem desigualdades entre os setores analisados: a maior parte dos domicílios (99,9\%) está ligada à rede geral de abastecimento de água, 98,7\% têm esgotamento sanitário via rede geral e 99,5\% têm lixo coletado por serviço de limpeza urbana. Para além dos problemas de qualidade destes serviços, sua distribuição é desigual, dado que a maior parte dos domicílios não incluídos nestes percentuais está concentrada no setor censitário apontado como problemático pelos ACEs e o único daquela AA com Índice de Vulnerabilidade em Saúde (IVS) de alto risco. No local, existem domicílios com esgotamento via vala (a céu aberto), alguns moradores utilizam caçambas ou enterramento em terreno baldio como formas de eliminar o lixo produzido; e o abastecimento de água é feito a partir de poços (IBGE, 2001).

Apesar de toda a área de abrangência do estudo ser classificada como "urbana" (IBGE, 2011), existem elementos rurais, como construções horizontais com quintais; criação de animais domésticos (cães, aves, gatos) e cultivo de alimentos (principalmente frutas). Tais fatores, associados às condições socioeconômicas da população, interferem na ocorrência de zoonoses, tais como a leishmaniose visceral, que no triênio 2008-2010 teve uma média de 4,4 casos humanos/ano, dado que caracteriza Morros Ávidos como área de transmissão intensa da doença (Brasil, 2006).

A despeito destes aspectos, as ações de prevenção e controle de zoonoses são focadas principalmente no controle dos elementos da cadeia epidemiológica (vetores e reservatórios), a partir do apelo dos ACEs, durante as visitas domiciliares, para que moradores mudem de comportamento. Ademais, muitas vezes, os agentes trabalham de forma segmentada, por agravo, como no estudo em questão, em que atuam dois grupos, a equipe fixa e a volante. A equipe fixa atua dentro dos limites da área de abrangência de Morros Ávidos, focada na prevenção e controle da dengue, havendo uma proposta de integração de suas atividades (vigilância em saúde) com as equipes de saúde da família (atenção básica à saúde). Já a equipe volante é voltada à prevenção e controle de leishmaniose visceral em diversas áreas de abrangência, sendo Morros Ávidos um dos locais. 
A opção do município por atuar em uma base territorial, compatível com as equipes da Atenção Básica, objetiva facilitar o reconhecimento e adequação das ações aos problemas em saúde da população e favorecer a integralidade na atenção à saúde (Brasil, 2010). Além disso, auxilia na identificação de fatores de risco e de proteção à saúde, que são essenciais para o planejamento e execução de ações articuladas. Como forma de incentivar a integração territorial da Vigilância em Saúde e Atenção Básica, o Ministério da Saúde criou um fundo para os municípios que aderissem tal proposta, divulgado na Portaria $\mathrm{n}^{0}$ 1007, de 04 de maio de 2010 (Brasil, 2010). Todavia, apenas a equipe fixa cumpre o papel de integração com o território, visto trabalho dentro dos limites da área de abrangência; a equipe volante atua em diversos locais (do mesmo distrito sanitário). Esta organização contribuiu para que a equipe fixa tenha mais conhecimento sobre o território e a população do que a equipe volante.

O esforço de incorporação gradativa dos ACEs às equipes de Saúde da Família, visando à participação no planejamento e programação das ações (Brasil, 2010), foi observado em Morros Ávidos. Neste contexto, é preciso que as atividades dos Agentes Comunitários de Saúde (ACSs) e dos Agentes de Combate a Endemias (ACEs) sejam desempenhadas de forma integrada e complementar; ambos devem assumir a corresponsabilidade pelo controle das doenças e conjugar suas atividades de forma a potencializar e melhorar a efetividade das ações (Brasil, 2010). Em Belo Horizonte, uma das atividades oferecidas pela Atenção Básica dos centros de saúde refere-se à "prevenção de doenças transmitidas por animais". Quer dizer, embora a equipe fixa de zoonoses seja considerada da vigilância em saúde, pelo fato de ocupar o mesmo território de abrangência da atenção básica, ela passa a integrá-la; mas essa posição de apoio ainda não está consolidada. Segundo relatos de agentes, não há um reconhecimento dos próprios profissionais do centro de saúde quanto ao papel da equipe de zoonoses. Contribui ainda para não integração a não inclusão dos ACEs no site institucional da Prefeitura de Belo Horizonte ([2011]), em seção sobre os centros de saúde e seus profissionais.

Por mais que estejamos dentro do centro de saúde, ainda há colegas de trabalho que também acham que zoonoses é zoonoses, que não serve pra muita coisa, que é muito fácil nosso trabalho. Aí dá pra ver que os profissionais não entendem que nosso trabalho é muito difícil na questão de mudar ambientes, mudar conceitos de pessoas.

A despeito de tanto os ACSs quanto os ACEs serem responsáveis por ações de educação em saúde, certas características de suas funções dificultam uma integração de suas atividades. Cabe salientar que os ACEs têm o papel de controlar as endemias pela inspeção e tratamento de focos, o que tende a identificá-los como responsáveis pelo cuidado do ambiente exterior à casa. Já os ACSs desenvolvem ações básicas de saúde voltadas para a orientação da população sobre os cuidados no interior da casa. O fato de as mulheres atuarem predominantemente como ACSs e os homens como ACEs reitera as convenções tradicionais de gênero expressas pelo papel feminino de cuidar da casa e da função masculina atrelada à rua (Oliveira, 2002).

Outra limitação da integração entre ACS e ACE na organização do processo de trabalho refere-se à definição de base territorial de atuação e a lógica de trabalho no território, distintas em relação à unidade base. Em Morros Ávidos, o Agente Comunitário de Saúde trabalha em uma microárea, vinculado a uma equipe de saúde da família, e sua unidade de atuação são as pessoas/famílias (no máximo 750 pessoas/ACS). 0 Agente de Combate a Endemias trabalha com diferentes lógicas de atuação; não existe uma preconização uniformizada, predomina uma forma segmentada, por agravo (Brasil, 2010). Além da unidade base diferente, as ACSs percorrem suas microáreas em função de ruas e os ACEs seguindo os quarteirões. Em Morros Ávidos, as equipes estão em um período de adaptação e tentativa de unificação na forma de percurso do território.

\section{Perfil e identidade profissional}

Entre os 16 agentes, havia apenas quatro mulheres, possivelmente pelas condições do trabalho, que demanda força física. 0 edital de seleção não diferencia as funções segundo o gênero (Prefeitura de Belo Horizonte, 2008), todavia na prática havia uma divisão entre as tarefas femininas e masculinas, como já assinalado. 0 grupo foi bastante heterogêneo quanto à idade, sendo a média etária de 33 anos. A maioria 
dos agentes tem ensino médio completo, apesar de o nível exigido para o cargo ser o ensino fundamental. Na equipe fixa, existem ACEs cursando ou tendo concluído ensino superior. A procura por qualificação pessoal e escolaridade foi justificada pelo desejo de mudança de profissão, em virtude da baixa remuneração e da instabilidade do vínculo empregatício. A renda mensal familiar média declarada foi entre um e três salários mínimos, sendo que a maioria dos agentes $(69 \%)$ tem outras fontes de renda, através de vínculos formais ou não.

A indefinição da categoria ocupacional "Agente de Combate a Endemias", a falta de investimento na capacitação profissional, a baixa remuneração, o precário vínculo empregatício e as condições de trabalho colaboram para a fragilização da identidade profissional dos ACEs. Tal situação pode ser compreendida pelo fato de as ações de controle de endemias, historicamente, terem sido centralizadas pela esfera federal, através da Funasa. A partir de 1999, seguindo os princípios do SUS de descentralização, as ações de vigilância foram assumidas pelos municípios. Apenas em 2006 foi oficialmente criada e regulamentada a ocupação de ACE, juntamente com a de ACS (ACS), através da Lei Federal 11.350. Em Belo Horizonte, tais cargos foram criados pela Lei 9.490, em 2008. No Código Brasileiro de Ocupações (Brasil, 2002), há referência apenas à categoria de ACS, sendo os títulos "Visitador Sanitário" e "Guarda de Endemias" os que mais se aproximam das suas funções e atividades ${ }^{3}$. Existem no País outras denominações para o cargo e discute-se a necessidade de unificação da denominação destes profissionais, sendo "Agentes de Vigilância em Saúde" o termo mais aceito (Brasil, 2010). 0 depoimento abaixo ilustra a percepção da fluidez da categoria profissional:

Acho que deveriam criar um nome específico mesmo, que seja registrado no Ministério do Trabalho, porque a gente não tem essa classificação.

Um dos principais problemas da descentralização foi a precarização do vínculo empregatício de grande parte dos agentes, uma vez que não existe um piso salarial comum aos diversos tipos de vínculos.
Atualmente, a Lei Federal 11.350 regulamenta que o trabalho dos ACEs deve se dar exclusivamente no âmbito do SUS e por meio de seleção pública, sendo proibida a contratação temporária ou terceirizada, exceto nos casos de surtos endêmicos. Em Belo Horizonte, os agentes efetivados a partir de 2008 devem estar sob o regime jurídico estabelecido pela Consolidação das Leis de Trabalho e o Regime Geral de Previdência Social. Porém, ainda existem funcionários com vínculo de estatutário, o que resulta em salário maior e mais benefícios, e gera conflitos entre os agentes.

Nós somos considerados apoio pro Programa Saúde da Família, apesar de não recebermos por isso. Só os agentes antigos, os agentes sanitários, é que recebem por isso a verba do plus [...] Nós, enquanto celetistas, que executamos o mesmo serviço, não recebemos. Isso é uma briga nossa [...].

A tensão entre a estabilidade e flexibilização (ou fragilização) do vínculo empregatício tem relação direta com o modelo neoliberal adotado pela maioria dos países. Em um polo estão os princípios igualitários e de universalidade que orientaram a Reforma Sanitária, expressa pela isonomia salarial nos planos de cargos, carreiras e salários e na estabilidade do servidor público. Em outro polo, a atual conjuntura econômica demanda uma flexibilização na contratação e remuneração, em decorrência das mudanças no mundo do trabalho, na economia mundial e nas perspectivas de descentralização. Uma vez que não há como negar tal tensão, o vínculo de celetista, quando comparado ao contrato temporário ou à terceirização, surge como um meio termo entre os interesses do trabalhador e das instituições (Nogueira, 1996).

Apesar dos problemas assinalados, a rotatividade nas duas equipes não é alta e muitos agentes estão há mais de 10 anos no serviço, o que parece contribuir para uma visão mais crítica em relação ao cargo e suas atribuições. A análise da formação profissional dos agentes e a organização do processo de trabalho complementa a reflexão acerca da identidade profissional e das implicações para a prática dos ACEs.

3 A ausência de referência à categoria ocupacional "Agente de Combate a Endemias" também foi observada na lista de Descritores em Ciências da Saúde (Bireme), na qual o termo que mais se aproximou às atividades e funções dos ACEs foi "Agentes Comunitários de Saúde”. 


\section{Formação profissional e práticas educativas}

Como consequência da descentralização das ações de vigilância em saúde, coube à Funasa capacitar e ceder aos Estados e municípios seus 26 mil agentes. A partir de guias ou cartilhas, a formação dos agentes era dissociada de base científica ou de conteúdos mais amplos, estando restrita aos saberes técnicos para o controle de endemias e/ou zoonoses (Torres, 2009). A despeito das mudanças ocorridas, principalmente após a Reforma Sanitária e a Lei Federal 11.350, que instituiu a obrigatoriedade de curso introdutório para o exercício das atividades dos ACEs aprovados em seleções públicas, o modelo vigente do curso introdutório ainda é pautado na transmissão de informações. A formação ocorre após o começo das atividades profissionais, havendo um intervalo de seis meses a um ano entre o início da atuação dos agentes e a capacitação. Ademais, não há um processo planejado, contínuo e permanente de formação; reproduz-se a cultura de que a educação é uma ação simples, que não exige planejamento ou qualificação específica dos formadores. Alguns agentes indicaram meios para amenizar o impacto deste padrão na formação profissional:

Eu acho que deveria ser colocado na grade de atividades do nosso serviço cursos. A gente devia tirar uma hora por dia pra sentar e discutir questões do dia a dia, que são dúvidas, sugestões.

Todos os agentes classificaram o processo de formação profissional como ruim, em virtude da ausência ou baixa frequência de cursos e palestras, da qualidade dos formadores e da oferta desigual de capacitações para os diferentes grupos de ACEs. Os agentes da equipe fixa parecem ter vantagens quanto à oferta de capacitação, quando comparados à equipe volante, em decorrência da posição de "pertencimento" ao centro de saúde e do acesso aos cursos oferecidos pela Atenção Básica. De acordo com os ACEs, a ausência de investimento no processo de qualificação decorre da preocupação com a produtividade, da falta de espaço físico para realização dos encontros, do não interesse da coordenação em organizar eventos educativos e do não compartilhamento de conhecimentos com os agentes: eles parecem que têm medo que a gente saiba mais que eles.

Os relatos indicaram a significação do saber téc- nico-científico como um poder, sendo a deficiência de capacitação tida como forma de os coordenadores se diferenciarem e exercerem poder sobre os ACEs. Tal aspecto foi igualmente observado na relação dos ACEs com a população. Os agentes se percebem como detentores do saber - logo, do poder - e como "filtros" ou "tradutores" do conhecimento técnico-científico para os moradores locais.

...gostaria de saber tudo, na íntegra, nome científico... Eu sei grosseiramente, émuito pouco pra minha formação [...] Olha, a gente não tem capacitação pra isso, mas devido à experiência de tanto tempo de trabalho, a gente vai adquirindo com esse tempo. Então se a gente identifica algum problema com relação ao cão, o dono dele é orientado, até onde o morador precisa de informação [...] O que a população interessa saber quantas perninhas tem o mosquito? $\varepsilon$ vai eliminar o problema da população? Mas eu queria saber sobre isso, sabe, acho importante pra mim. Pra população não interessa, mas pra mim, que sou profissional, seria muito bom.

Os coordenadores concordam com os diversos problemas apontados pelos ACEs referentes à capacitação, mas citam causas distintas, como: a rotatividade de pessoal entre equipes e falta de tempo dos próprios coordenadores decorrente da sobrecarga de trabalho. A escassa capacitação oferecida aos ACEs não condiz com o discurso institucional sobre o papel central de educador, tendo em vista a prática educativa em saúde enquanto ação sistematizada e planejada. Os dados apresentados indicam a precariedade e falta de investimento na formação dos ACEs e assemelham-se aos achados de Oliveira (2002), que observou graves deficiências na capacitação dos ACEs de Camaragibe e seus impactos negativos na autoestima do grupo.

A organização do processo de trabalho para o controle de endemias teve origem nas experiências dos serviços de saúde dos exércitos coloniais e no modelo biomédico para explicação da ocorrência de doenças. As ações eram estruturadas a partir de campanhas sanitárias de forte caráter militar; apesar de antidemocrática e distante dos interesses das classes populares, era coerente com o conceito de saúde das políticas de controle de endemias naquele momento histórico. Posteriormente, esta linha de atuação foi reforçada e viabilizada pelas teorias 
normativas de planejamento e gestão. A acentuada centralização destas ações provocou a separação entre planejamento e execução, estabeleceu metas objetivas e, em sua maior parte, quantificáveis, sendo guiadas pela lógica da produção industrial (Oliveira, 2002).

O novo conceito ampliado de saúde, relacionado ao entendimento do processo saúde-doença como um evento complexo e determinado por condicionantes individuais, ambientais, sociais, econômicos e políticos aponta para a necessidade de trilhar novos caminhos no controle de endemias. Tal perspectiva implica a revisão da atuação dos ACEs, visando avançar na compreensão dos problemas de saúde das famílias e das populações, assim como nas observações dos fatores socioambientais e econômicos associados às endemias ${ }^{4}$.

No entanto, o modelo de organização e gerenciamento do serviço de controle de zoonoses e do processo de trabalho dos ACEs em Belo Horizonte é fragmentado. $O$ controle e supervisão do serviço priorizam a relação hierarquizada; os ACEs são avaliados de acordo com a produtividade e pontualidade, havendo uma supervalorização da dimensão quantitativa da produção, o que revela a persistência do modelo organizacional da Funasa. A pressão pelo cumprimento de metas quantitativas também foi encontrada em trabalho desenvolvido por Chiaravalloti e colaboradores (2007), desenvolvido com agentes em São José do Rio Preto e por Guida e colaboradores (2012) com ACEs em Nova Iguaçu. A questão não é a renúncia às contribuições desses instrumentos de medida para a racionalização do trabalho e planejamento e avaliação do serviço. Objetiva-se salientar os seus efeitos na limitação das ações dos ACEs em termos do enfrentamento das intercorrências cotidianas da vida nas comunidades e do envolvimento da população na definição das ações. Tais situações exigem dos agentes uma postura flexível e criativa que, por vezes, não se enquadra na estrutura organizacional do modelo gerencial, enrijecida pela ênfase na produtividade e na criação de normatizações e rotinas rígidas (Oliveira, 2002). 0 trabalho educativo, entendido pela perspectiva construtivista, dá-se na interação com as pessoas, portanto, é subjetivo e necessita de autonomia e criatividade.

Sem contar também que é aquele negócio né: produção, produção, produção. [...] Você tem que dar uma orientação melhor e muitas das vezes a orientação fica falha. Esse negócio de querer produção, produção, eu acho que é muito complicado, porque na verdade a gente não énem técnico em zoonoses, a gente não é um agente específico, a gente é um passador de informação. A partir do momento que eu te faço uma orientação bacana, você tá imbuída de me escutar, essa minha orientação vai fazer uma diferença.

Há uma tentativa do nível central do serviço de controle de zoonoses para que os ACEs participem do processo de elaboração de políticas, mas o entendimento sobre este engajamento reflete a tradição dominante do conceito de participação popular (Valla, 1998). Os agentes são convidados a participar para legitimar processos e decisões tomadas por outros profissionais e para solucionarem problemas que não dão conta. Durante a reunião entre coordenadores e agentes, observou-se que os ACEs foram convidados a se manifestar mais como prova do compromisso com a democracia do que com o real interesse de valorização do saber daqueles profissionais. Tal situação tende a gerar resistências e falta de motivação, resultando em um agir descompromissado e descolado da missão institucional.

A adoção dos princípios da educação construtivista, centrados no diálogo, na problematização e na participação, poderia contribuir no resgate desses ruídos e na reorientação global dos serviços, tornando-os mais humanizados e adequados às necessidades da população e dos trabalhadores. Deste modo, facilitaria o estabelecimento de uma ação comunicativa entre os diversos atores sociais, potencializando a leitura crítica da realidade para o diagnóstico participativo e o planejamento estratégico (Raupp e col., 2001). Como citado, os ACEs têm grande potencial para atuar como educadores no âmbito dos serviços de controle de zoonoses, pois estão cotidianamente em relação com a comunidade.

4 BARCELlOS, C.; ROJAS, L. I. O território e a vigilância da saúde. Rio de Janeiro: Escola Politécnica de Saúde Joaquim Venâncio, 2004. (Programa de Formação de Agentes Locais de Vigilância em Saúde (Proformar), Unidade de Aprendizagem I, Módulo III). 
No entanto, no contexto investigado, as atividades educativas praticadas pelos agentes restringiam-se às orientações aos moradores durante as visitas domiciliares, prevalecendo o caráter individual. Apenas a equipe fixa pontuou algumas ações coletivas, como palestras em escolas.

Quando questionados sobre suas funções enquanto ACE, a maioria descreveu atividades de fiscalização de imóveis e ações educativas, visando à prevenção de zoonoses. Esta duplicidade de atuação do agente, policialesca e educativa, tem raízes históricas (Acioli e Carvalho, 1998). A partir do trabalho de campo pode-se inferir que a concepção de educação em saúde que orienta os ACEs é normativa e fortemente associada ao modelo biomédico. Há uma desvalorização dos saberes, incompreensão das lógicas populares e certa culpabilização da população por seus problemas de saúde. Predominam ações educativas voltadas para a mudança de comportamentos e hábitos individuais, centradas na procura e controle de focos, criadouros de vetores e reservatórios de zoonoses. Tal resultado reflete as vivências destes agentes em relação à educação pautadas em teorias não críticas e na falta de investimento institucional na sua formação. Há pouco espaço no serviço para atuação e reflexão dos ACEs relativas aos determinantes e condicionantes socioeconômicos e ambientais associados ao desenvolvimento de zoonoses, tais como as condições de vida, os problemas e as necessidades da população.

A legitimidade da centralidade da transmissão do conteúdo, descrita na concepção educação bancária (Freire, 2011), é coerente com a percepção de que a população é ignorante, expressa pela visão depreciativa dos ACEs sobre os moradores, caracterizada pelo uso de adjetivos pejorativos, como ilustrado pelo depoimento:

Sempre tem aqueles que não veem a gente com bons olhos, acha que a gente fica inventando, que o governo inventou isso. Falam que não existe dengue, que isso é invenção do governo pra ficar dando emprego pros outros. É uma bobajada danada, geralmente é gente ignorante, mais ou menos esclarecido né, ou ignorante mesmo.

A maioria das propostas dos serviços de controle de zoonoses pressupõe a categoria intitulada por Valla (1996) como “previsão”, associada à prevenção, ao futuro. Todavia, entre a população de baixo poder aquisitivo prevalece a categoria de "provisão", relacionada à necessidade de enfrentar as dificuldades de sobrevivência cotidianamente. A incompreensão dessa lógica popular gera conflitos entre os interesses dos serviços públicos e as reais necessidades da população. Em estudo no interior de Minas Gerais, Dias (1998) identificou que, apesar da alta prevalência de Doença de Chagas no local, o tratamento não era considerado prioritário pela população e sim mais um problema diante da luta cotidiana para satisfazer necessidades imediatas.

Outro desafio dos ACEs refere-se às atividades que envolvem cães, por abarcarem a perspectiva da afetividade entre o morador e seu animal de estimação. Segundo os agentes, nestas situações é difícil convencer os moradores a seguirem as determinações do serviço de saúde relativas à eutanásia do cão perante o diagnóstico positivo de LV. Neste sentido, foi assinalada pelos agentes a necessidade de uma capacitação para lidar com as reações da população diante da comunicação do resultado positivo para leishmaniose visceral em cães de estimação. Cabe destacar que a epidemia de LV em BH suscitou diversos debates sobre a validade do teste diagnóstico utilizado pela SMSA-BH. Tais incertezas geraram desconfiança nos clínicos veterinários da região e nos proprietários de animais, contribuindo para a resistência quanto à entrega do animal considerado positivo. Ademais, muitas vezes o cão está aparentemente sadio, em função do padrão de ocorrência da LV. No Brasil, a forma assintomática da doença é encontrada em índices variáveis, representando em média 40 a $60 \%$ da população soropositiva. 0 fato de o serviço de controle de zoonoses afirmar que o animal está infectado, após realização de exame, e a não observação de sinais clínicos pode alimentar a dúvida sobre a validade do resultado e aumentar a resistência em aceitar a norma de entrega do animal para a eutanásia.

A incompreensão da lógica e dos saberes populares vai além. $\mathrm{O}$ agente se vê como único detentor de saber na relação com a população carente, o que o coloca em situação de poder. Neste contexto, a informação é considerada quase uma dádiva, pois muitos ACEs reforçam a importância e o prazer de seu trabalho a partir do compartilhamento de seus 
conhecimentos técnicos com a população, a fim de melhorar sua condição de saúde. 0 não atendimento das recomendações é entendido pelos ACEs como indicativo de falta de informação, comodismo e/ou impossibilidade de escolha. Por sua vez, a população normalmente reconhece o agente como porta de entrada para reclamações e exposição de demandas que vão além da presença de vetores e doenças. A distância entre a lógica popular e a atuação do serviço público favorece o descrédito da população quanto às competências do agente e interfere na sua atuação (Chiaravalloti e col., 2007).

Apesar de os relatos e as práticas dos agentes se aterem aos elementos biológicos das zoonoses, alguns reconhecem que o desenvolvimento das doenças não está relacionado apenas aos hábitos e costumes da população. Foram ressaltados aspectos das condições de vida que reduzem o processo de culpabilização dos sujeitos, ilustrados nas falas seguintes:

Eles (governo) querem jogar pra cima da população uma coisa que a população tá sofrendo e que a população não vai resolver isso se a gente não ajudar. Você tem todos os lotes e casas aqui com quintais. Então acaba tendo encostas, onde precisa do mato pra segurar. Quem tem condições faz um muro de arrimo, mas que não tem deixa o mato crescer pra segurar o barranco, pra segurar a casa.

O reconhecimento das carências experimentadas pelas classes populares não foi acompanhado de uma percepção de que esses grupos sociais têm capacidade de produzir conhecimentos e se organizar para criar estratégias de transformação. Ressaltou-se que os moradores não adotam as recomendações dos ACEs para o controle das zoonoses por terem outras prioridades, como revelam os seguintes depoimentos:

Gente, o pessoal não vai deixar de ter fruta no quintal por causa de leishmaniose.

A maioria cuida desse negócio de ração de cachorros, fezes de cachorro no quintal não por causa da leishmaniose, mas porque a maioria tem certo pavor ao roedor.

Quanto ao uso de materiais educativos, observou-se que não há envolvimento dos ACEs no processo de elaboração dos recursos, que muitas vezes são enviados aos agentes sem qualquer orientação, apenas com a ordem de repasse ao morador. A entrega dos materiais, por si só, foi considerada por muitos uma ação educativa, o que indica o uso instrumental destes recursos educativos. Além disso, observou-se priorização de panfletos, característico de ações pontuais. Os achados descritos indicam que a realidade do serviço, a partir do planejamento de ações centralizadas, compromete o processo de construção compartilhada das ações educativas e da produção e uso dos materiais educativos, visando abranger interesses e saberes da instituição, dos ACEs e da população. Isto aumenta a distância entre os profissionais e as realidades locais e entre os objetivos da instituição e o cotidiano de trabalho enfrentado pelos ACEs.

\section{Considerações finais}

A análise das práticas educativas dos ACEs, de modo contextualizado, permitiu a observação de inúmeros entraves à incorporação do modelo participativo de educação em saúde que transcendem os aspectos individuais, relacionados aos agentes, tais como: a cultura institucional medicalizadora; o processo de trabalho fragmentado e itinerante; a precarização das condições de trabalho dos profissionais; a fragilização do vínculo empregatício dos agentes e a baixa remuneração; o planejamento centralizado e verticalizado das ações; a falta de investimento na formação dos ACEs; a organização da rotina dos agentes de acordo com agravos e a cobrança por produção, medida basicamente por parâmetros quantitativos.

A revisão da forma de organização do serviço e investimentos na formação dos ACEs, centrados na multideterminação do processo saúde-doença, nos fundamentos educacionais dialógicos e participativos e na importância do contexto socioeconômico e ambiental no controle das zoonoses, podem contribuir para o entendimento das dificuldades e resistências populares ao discurso técnico científico e a revisão das atividades educativas desenvolvidas pelos ACEs.

Para a operacionalização das indicações assinaladas, torna-se fundamental o desenvolvimento de 
projetos de educação permanente para os ACEs e seus coordenadores, assim como apoio sistemático no campo e reuniões periódicas, para fortalecimento teórico e metodológico dos agentes. Quanto ao reforço à integração entre Atenção Básica e Serviço de Controle de Zoonoses local, cabe auxílio técnico para redefinição do processo e rotina de trabalho dos profissionais envolvidos no serviço de controle de zoonoses e na Atenção Básica, com destaque para os ACEs e ACSs, através de uma pactuação da missão institucional do papel destes sujeitos. Tal enfoque pode contribuir para o estabelecimento de uma cultura de corresponsabilização e para o envolvimento de outros órgãos, como as Secretarias de Educação e a de Meio Ambiente, visando a ações intersetoriais no território.

\section{Colaboração dos autores}

Fraga foi responsável pelo desenvolvimento do estudo, pela análise dos dados e pela redação do artigo. Monteiro participou da concepção do estudo, da revisão da análise dos dados e da redação do artigo.

\section{Referências}

ACIOLI, M.; CARVALHO, F. Discursos e práticas referentes ao processo de participação comunitária nas ações de educação em saúde: as ações de mobilização comunitária do PCDEN/PE. Cadernos de Saúde Pública, Rio de Janeiro, v. 14, p. 59-68, 1998. Suplemento 2.

ARREGUY, C.; RIBEIRO, R. (Org.). Histórias de bairros de Belo Horizonte: regional noroeste. Belo Horizonte: Arquivo Público da Cidade de Belo Horizonte (APCBH): Associação Cultural do Arquivo Público da Cidade de Belo Horizonte (ACAP-BH), 2008.

BARDIN, L. Análise de conteúdo. Lisboa: Edições 70, 2009.

BELAVICQUA, P. D.; MODENA, C. M.; PAIXÃO, H. H. Urbanização da leishmaniose visceral em Belo Horizonte. Arquivo Brasileiro de Medicina Veterinária e Zootecnia, Belo Horizonte, v. 53, n. 1, p. 1-8, 2001.
BRASIL. Ministério do Trabalho e Emprego. Classificação Brasileira de Ocupações. Brasília, DF, 2002. Disponível em: <http://www.mtecbo.gov. br/cbosite/pages/pesquisas/BuscaPorTituloA-Z. jsf $>$. Acesso em: 17 set. 2011.

BRASIL. Ministério da Saúde. Secretaria de Vigilância em Saúde. Manual de vigilância e controle da leishmaniose visceral. Brasília, DF, 2006.

BRASIL. Ministério da Saúde. Secretaria de Vigilância em Saúde. Manual técnico de Centros de Controle de Zoonoses. Brasília, DF, 2007.

BRASIL. Ministério da Saúde. Portaria nº 1007, de 4 de maio de 2010. Define critérios para regulamentar a incorporação do Agente de Combate às Endemias - ACE, ou dos agentes que desempenham essas atividades, mas com outras denominações, na atenção primária à saúde para fortalecer as ações de vigilância em saúde junto às equipes de Saúde da Família. Diário Oficial da União, Brasília, DF, 5 maio 2010. Seção I, p. 36-37.

CHIARAVALLOTI, F. et al. O programa de controle do dengue em São José do Rio Preto, São Paulo, Brasil: dificuldades para a atuação dos agentes e adesão da população. Cadernos de Saúde Pública, Rio de Janeiro, v. 23, n. 7, p. 1656-1664, 2007.

DIAS, R. "Eu? Eu estou aí, compondo o mundo": uma experiência de controle de endemia, pesquisa e participação popular vivida em Cansanção, Minas Gerais, Brasil. Cadernos de Saúde Pública, Rio de Janeiro, v. 14, p. 149-157, 1998. Suplemento 2.

FREIRE, P. Pedagogia do oprimido. São Paulo: Paz e Terra, 2011.

IBGE - INSTITUTO BRASILEIRO DE GEOGRAFIA E ESTATÍSTICA. Censo demográfico 200o: características da população e dos domicílios: resultados do universo. Rio de Janeiro, 2001. Disponível em: <http://www.ibge.gov.br/home/ estatistica/populacao/censo2ooo/default.shtm>. Acesso em: 3 out. 2011.

IBGE - INSTITUTO BRASILEIRO DE GEOGRAFIA E ESTATÍSTICA. Censo demográfico 2010. Rio de Janeiro, 2011. Disponível em: <http://www. cens02010.ibge.gov.br/>. Acesso em: 10 out. 2011. 
GUIDA, H. F. S. et al. As relações entre saúde e trabalho dos agentes de combate às endemias da Funasa: a perspectiva dos trabalhadores. Saúde e Sociedade, São Paulo, v. 21, n. 4, p. 858-870, 2012.

MALINOWSKI, B. Tema, método e objetivo desta pesquisa. In: Argonautas do pacífico

ocidental: um relato do empreendimento e da aventura dos nativos nos arquipélagos da Nova Guiné, Melanésia. São Paulo: Abril Cultural, 1984. p. 17-34.

MINAYO, M. C. S. O desafio do conhecimento: pesquisa qualitativa em saúde. 12. ed. São Paulo: Hucitec, 2010.

NOGUEIRA, P. Estabilidade e flexibilidade: tensão da base nas novas políticas de recursos humanos em saúde. Divulgação em Saúde para Debate, Londrina, n. 14, p. 18- 22, ago. 1996.

OLIVEIRA, R.; VALLA, V. As condições e as experiências de vida de grupos populares no Rio de Janeiro: repensando a mobilização popular no controle do dengue. Cadernos de Saúde Pública, Rio de Janeiro, v. 17, p. 77-88, 2001. Suplemento.

OLIVEIRA, M. V. A educação popular em saúde e a prática dos agentes de controle das endemias de Camaragibe: uma ciranda que acaba de começar. 2002. Dissertação (Mestrado em Educação) Programa de Pós-Graduação em Educação da Universidade Federal da Paraíba, João Pessoa, 2002.

PORTO, M. F. Entre a prevenção e a precaução: riscos complexos e incertos e as bases de uma nova ciência da sustentabilidade. In: MIRANDA, A. C. et al. (Org.). Território, ambiente e saúde. Rio de Janeiro: Fiocruz, 2008. p. 143-158.

\section{PREFEITURA DE BELO HORIZONTE. Edital de} seleção de agentes de combate a endemias, 2008. Belo Horizonte, 2008. Disponível em: <http://www. pciconcursos.com.br/concurso/prefeitura-de-belohorizonte-mg-2351-vagas $>$. Acesso em: 18 julho 2011.
PREFEITURA DE BELO HORIZONTE. Secretaria Municipal de Saúde. Gerência de Atenção Primária. Centros de Saúde. Belo Horizonte, [2011]. Disponível em: <http://portalpbh.pbh.gov.br/pbh/ ecp/comunidade.do?evento=portlet\&pIdPlc=ecpTa xonomiaMenuPortal\&app=saude \&tax=19981\&lan $\mathrm{g}=$ pt_BR\&pg=5571\&taxp=o\&>. Acesso em: 18 maio 2014.

RAUPP, B. et al. A vigilância, o planejamento e a educação em saúde no SSC: uma aproximação possível? In: VASCONCELOS, E. M. (Org.). A saúde nas palavras e nos gestos: reflexões da rede de educação popular em saúde. São Paulo: Hucitec, 2001. p. 207-216.

RIBEIRO, P. et al. Programa educativo em esquistossomose: modelo de abordagem metodológica. Revista de Saúde Pública, São Paulo, v. 38, n. 3, p. 415-421, 2004.

SANTOS, M. Toxocaríase: avaliação do processo ensino-aprendizagem de recursos pedagógicos aplicados a crianças do ensino fundamental. 2003. Dissertação (Mestrado em Medicina Veterinária) Faculdade de Medicina Veterinária e Zootecnia da Universidade de São Paulo, São Paulo, 2003.

SANTOS, A. Inovações no ensino de ciências e na educação em saúde: um estudo a partir do projeto Finlay. 2005. Dissertação (Mestrado em Educação) - Faculdade de Educação da Universidade de São Paulo, São Paulo, 2005.

SCHRAMM, J. et al. Transição epidemiológica e o estudo de carga de doença no Brasil. Ciência \& Saúde Coletiva, Rio de Janeiro, v. 9, n. 4, p. 897908, 2004.

THOMPSON, P. A voz do passado. São Paulo: Paz e Terra, 1992.

TORRES, R. Agentes de combate a endemias: a construção de uma identidade sólida e a formação ampla em vigilância são desafios dessa categoria. Revista Poli: Saúde, Educação e Trabalho, Rio de Janeiro, n. 3, p. 16-17, jan./fev. 2009. 
UCHOA, E. et al. The control of schistosomiasis in Brazil: an ethnoepidemiological study of the effectiveness of a community mobilization program for health education. Social Science \& Medicine, New York, v. 51, n. 10, p. 1529-1541, 2000.

VALLA, V. A crise da compreensão é nossa: procurando compreender a fala das classes populares. Educação e Realidade, Porto Alegre, v. 21, n. 2, p.177-190, 1996.

VALLA, V. Sobre participação popular: uma questão de perspectiva. Cadernos de Saúde Pública, Rio de Janeiro, v. 14, p. 7-18, 1998. Suplemento 2.
VASCONCELOS, E. Educação popular e pesquisaação como instrumentos de reorientação da prática médica. In: GONSALVES, E. P. (Org.). Educação e grupos populares: temas recorrentes. São Paulo: Alínea, 2002. p. 99-116.

WHO - WORLD HEALTH ORGANIZATION. First WHO report on neglected tropical diseases: working to overcome the global impact of neglected tropical diseases. Geneva, 2010. 